\section{Benefits of trade in amber fossils}

Amber of great palaeontological significance is flowing into China's jewellery market, fuelling a trade that dates back some 13,000 years. Ironically, banning this trade could be more damaging to science than letting it continue.

Fossiliferous ambers are being extensively destroyed by mining activity. The renowned Zhangpu amber from southeast China, for example, is being burned in the process of kaolin extraction. The Fushun amber site is closing after more than 110 years of adjacent lignite mining (B. Wang et al. Curr. Biol. 24, 1606-1610; 2014).

Amber affords exceptional preservation of insects and microorganisms, shedding light on ephemeral behaviours such as parasitism, predation and camouflage. These fossils often provide more detail than rock fossils about an organism's morphology, ecology, ethology and evolutionary history (see, for example, D.-Y. Huang et al. Sci. Rep. 6, 23004; 2016).

Amber excavation involves manpower and materials that are not available to palaeontologists. The jewellery trade instead provides them with the organismal inclusions, either directly as unwanted material or indirectly by preserving the fossils in finished gems for posterity. Jun Chen Linyi University, China. Bo Wang Nanjing Institute of Geology and Palaeontology, China. Edmund A. Jarzembowski Natural History Museum, London, UK. rubiscada@sina.com

\section{Postdoc rights need not hurt productivity}

Portugal's government is on the verge of a historic process, recognizing at last that postdoctoral researchers should have the same rights as the rest of the country's workforce (see go.nature.com/famkkn; in Portuguese). In defiance of European Union practice, more than $90 \%$ of these early-career scientists are currrently classed as 'advanced students' and funded by student scholarships.

Some institutions are expected to resist this change. The idea persists that big research teams boost scientific productivity, with postdocs offering the cheapest means of expansion.

Changing the scholarship system to non-tenured work contracts - comparable to postdoc fellowships in most developed countries - will mean losing roughly one-third of postdocs, assuming government funding stays the same. Even so, $96 \%$ of postdocs surveyed at the University of Minho support the change. A much bigger survey by the Portuguese National Association of Researchers in Science and Technology is expected to yield similar results.

International evidence indicates that reducing the number of postdocs by one-third is unlikely to impair productivity (see Nature 531, 263-265; 2016). Nuno Cerca University of Minho, Braga, Portugal. nunocerca@ceb.uminho.pt

\section{Ventilating Beijing cannot fix pollution}

Beijing plans to build a system of ventilation corridors across the city to help dissipate heat and smog (see go.nature.com/ cgbd7i). We suggest that a more comprehensive solution is needed to tackle the scale and complexity of Beijing's severe air pollution.

In our view, the city's situation in a valley ringed by mountains combined with the fall in average winter wind speed over the past decades (Z. Li et al. Adv. Atmos. Sci. 28, 408-420; 2011) - is likely to reduce the effectiveness of these corridors, particularly in winter, when smog is most severe. The prevailing northwesterly winter wind could also propel dangerous particulate matter and other pollutants along the corridors to the south of the city, where the wind gradually weakens and so is less effective at dispersal (X. He et al. Build. Environ. 92, 668-678; 2015).

Measures to control air pollution need to address causes as well as symptoms. Industrial structures, energy inefficiency, the pursuit of economic growth and the extent of regional cooperation all contribute (Y. Liu et al. Nature 517, 145; 2015).

These must eventually be brought into line through integrated, scientifically informed planning. Yansui Liu Beijing Normal University, China.

Yang Zhou, Yurui Li Institute of Geographic Sciences and Natural Resources Research, Chinese Academy of Sciences, Beijing, China.

liuys@igsnrr.ac.cn

\section{Anti-science wave sweeps Poland}

Poland's government is showing a worrying trend to disregard scientific evidence and rationality (see, for example, Nature 530, 393; 2016). Polish academia needs the backing of international scientific societies to help counter some alarming implications for the population.

For instance, we find it questionable that Poland's Parliamentary Committee on the Safety of the Programme of Vaccination of Children and Adults invited an anti-vaccination activist to speak as an expert at one of its meetings (see go.nature. com/6bbg5u; in Polish).

In addition, the country's in vitro fertilization (IVF) programme has been axed. This leaves some 17,000 couples stranded in mid-treatment and almost 22,000 others on the waiting list (see go.nature. com/nfuede; in Polish). And if proposed anti-abortion legislation goes through, IVF is likely to become illegal. The health ministry is developing an alternative programme based on natural procreative technology ('naprotechnology'), a fertility treatment that is approved by the Catholic Church but lacks sound scientific support.

Some Polish universities, such as the University of Gdańsk and the Medical University of Wrocław, are engaging speakers on such scientifically refuted topics as curing cancers with vitamin C or breast enlargement through hypnosis. Creationism, too, seems to be experiencing a resurgence. For example, the book Ewolucja, Dewolucja, Nauka (Evolution, Devolution, Science) Fronda, 2016) by the dendrologist Maciej Giertych, which we read as arguing against evolution, is being promoted in schools. In our view, this poses a threat to the country's scientific-education programme. Paula Dobosz University of Cambridge, UK.

Jakub Zawiła-Niedźwiecki University of Warsaw, Poland. jakub@zawila-niedzwiecki.pl

\section{Tell us the end of the story}

Nature's Correspondence section is known for highlighting political aspects of scientific issues of public interest and for calling on organizations and governments to address scientists' concerns in developing policy. Readers would surely like to know what happened next.

Contacting the authors could be enlightening, but readers' curiosity may not transcend their busy schedules. Perhaps correspondents should consider adding an online footnote to their letter to indicate its impact. M. Usman University of Agriculture, Faisalabad, Pakistan. A. Chaudhary Government College University, Faisalabad, Pakistan.

M. Farooq College of Veterinary and Animal Sciences, Jhang,

Pakistan. muhammad.usman@uaf.edu.pk 